Using Disciplinary Literacies to Enhance Adolescents' Engineering Design Activity

\author{
Amy Alexandra Wilson
}

Emma Smith

Daniel L. Householder

Utah State University 


\begin{abstract}
This comparative case study describes the literacy practices of two groups of adolescents as they sought to solve authentic problems through engineering design processes. Three types of data were collected as the groups addressed these problems: video- and audio-recordings of their conversations; adolescent-generated products; and pre- and post-challenge interviews. The authors used existing coding schemes of engineering design activity to identify when the adolescents enacted different stages of engineering design, as well as a modified form of constant comparative analysis to identify the literacy practices that corresponded with each stage. The analysis indicates that applications of literacy practices at each stage of the engineering design process enhanced the adolescents' overall design activity, whereas the absence of literacy practices often impeded the viability of their final designs. The authors suggest implications for high school engineering and science teachers who seek to enhance their students' design activity through literacy instruction.
\end{abstract}

Keywords: disciplinary literacy, engineering literacy, engineering design, adolescent literacy

Teaser Text: Engineering and literacy? Yes! Although science, mathematics, and technology are usually cited as partners to engineering, this article describes ways that literacy can enhance adolescents' engineering activity as well. 


\section{Using Disciplinary Literacies to Enhance Adolescents' Engineering Design Activity}

Over 56 million K-12 students are currently enrolled in some type of engineering coursework (Katehi, Pearson, \& Feder, 2009), a number that is only expected to increase due to the publication of the Next Generation Science Standards (NGSS Lead States, 2013), which require engineering principles to be integrated into K-12 science instruction. Moreover, within the United States, over 41 states include standards that address principles of engineering (Carr, Bennett, \& Strobel, 2012).

Despite this current and growing emphasis on K-12 engineering instruction, very little research has been conducted on how fundamental literacy — or the interpretation and production of texts (Norris \& Phillips, 2003)—can enhance adolescents' understanding and practice of engineering. The purpose of this comparative case study was therefore to examine the ways in which two groups of adolescents used reading and writing to solve authentic problems through engineering design processes.

\section{Disciplinary Literacy in Engineering}

A large and growing body of empirical and theoretical literature has argued that text interpretation and production are profoundly embedded within disciplinary activity (Moje, 2008). Within the discipline of engineering, one defining activity is design (Dym et al., 2005), described as "a systematic, intelligent process in which designers generate, evaluate, and specify concepts for devices, systems, or processes whose form and function achieve clients' objectives or users' needs while satisfying a specified set of constraints" (p. 104).

Although scores of engineering practitioners and researchers offer somewhat different descriptions of engineering design processes, most of them share several common elements that are iterative and non-linear in nature (Mehalik \& Schunn, 2006): 
- Define the problem. Designers identify the criteria and constraints that must be met, including ranking these criteria and constraints in terms of importance. As part of this process, designers gather information that shapes their understandings of these criteria and constraints, such as by asking questions to clarify clients' needs.

- Generate and evaluate solutions. Designers generate multiple solution elements and overall solutions, and they evaluate them according to how well they meet their criteria and constraints. They often construct models-including mathematical/visual models or physical prototypes - which help them to conceptualize and evaluate their proposed ideas.

- Realize solution. Designers decide on an overall solution after weighing alternatives. They communicate their solutions to clients, manufacturers, and/or other stakeholders who may work with them to physically implement their idea.

Engineering literacy has been defined in relation to the ability to use design processes to solve problems (e.g., National Assessment Governing Board, 2010). We argue that this type of engineering literacy derives largely from fundamental literacies, or the ability to locate, comprehend, evaluate, and produce discipline-specific texts. We draw this argument from Norris and Phillips' (2003) assertion that scientific literacy—including the ability to use methods of scientific inquiry to ask and answer questions — stems from what the authors called "fundamental literacy," or the comprehension and production of texts. By analogy, we entered this study with the assumption that adolescents' enactment of engineering design processes (engineering literacy) would likewise depend to a great extent on how they interpreted and generated texts (fundamental literacy). 
We sought to identify the adolescents' fundamental literacies by highlighting their literacy practices throughout the engineering design process. Our definition of literacy practice is informed by Heath's (1982) definition of literacy events, or "occasions in which written language is integral to the nature of participants' interactions and their interpretive processes and strategies" (p. 50). Street (2000) later argued that these observable interactions surrounding texts form relatively stable patterns, called literacy practices, to meet the needs and goals of particular social groups. For instance, engineers engage in literacy practices—-such as drawing and labeling visual models of their physical designs - that may seem foreign to historians whose disciplinary goals and traditions call for a different set of practices.

This study enabled us to explore whether certain literacy practices aided the adolescents' design processes. Specifically, we sought to answer the following research questions: (1) What literacy practices did the adolescents enact during each stage of the design process? (2) What literacy-related difficulties did the adolescents face? Ultimately, we hoped that the identification of these difficulties would point toward areas in which secondary engineering teachers could more fully use literacy instruction to support their students' engineering design activity.

\section{Method}

To answer these questions, we conducted a descriptive, comparative case study (Carmel, 1999) of two groups of 17 -year-olds as they sought to solve a problem through engineering design processes, which enabled us to compare and contrast how the same phenomenon (literacy practices in engineering) occurred within and across two cases.

\section{Participant Selection}

Because we did not provide engineering instruction to the adolescents prior to this study, we wanted to select participants who were already familiar with the process of using scientific 
and mathematical knowledge to solve problems related to the material world. Therefore, we recruited participants from a list of high school students who had attended Engineering State, a week-long summer institute in which students built a variety of structures and received feedback from engineers. In order to participate in Engineering State, the students had previously demonstrated excellence in science and mathematics courses.

We asked Engineering State participants who lived within a 60 -mile radius of our rural Western university if they were interested in addressing another engineering design challenge. We conducted an initial interview with respondents in order to discover his/her interests and career aspirations. From these interviews, we discovered that three adolescents either wanted to provide clean water to people in developing countries and/or had experience with land irrigation, while four adolescents wanted to help people with disabilities. Consequently, we developed two engineering challenges: one that addressed water distribution issues in Uganda, and another geared toward helping a man with muscular dystrophy.

\section{Development of Design Challenges}

We sought to develop design challenges that were 'authentic' in the sense that they aligned with the adolescents' interests; they met the needs of actual clients who would benefit from the devices; and they had no pre-determined pathway for solving the problem with no single correct solution ( National Center for Engineering and Technology Education, 2012). To develop the first challenge, we consulted with a civil engineer and a team leader for Engineers Without Borders who frequently visited an orphanage/boarding school in Uganda.

Together we wrote a design challenge that required the adolescents to redesign the school's water system. The participants' final design was presented to the team leader who had 
the option of implementing their design when his team visited the orphanage again. We refer to this group of two boys and one girl as the EWB Group.

To develop the second engineering design challenge, we consulted with a mechanical engineer and the lead technician of a local Assistive Technology Lab. A man with muscular dystrophy had recently approached the lab because he needed a better device for entering and exiting the bathtub. We asked the second group of participants to improve the man's current device, which was bowing. They presented their final design to the client and to the lab technician who said he would build the design if he thought it was promising. We refer to the group of two boys and two girls who addressed this challenge as the AT Group.

The current bathing transfer system was in the room with the AT Group as they met to address the challenge, whereas the EWB Group had maps of the orphanage and photographs of the current water-related structures there. We provided both groups with laptops so they could locate additional information related to the challenge. Moreover, we provided them with a mobile phone and gave them the phone numbers of the EWB team leader, the man with muscular dystrophy, and the technician at the Assistive Technology Lab.

\section{Data Collection}

We collected three types of data related to this project. First, we collected video- and audio-recordings of the adolescents as they addressed their respective challenges, which took three to four hours per group. The audio-recordings were later transcribed.

Second, we conducted individual pre- and post-challenge interviews with each participant, which lasted from 30-60 minutes per interview. In the pre-challenge interviews, which were conducted about a month before the challenge, we ascertained their interests and used them as the basis for the problem statement. In the post-challenge interviews, which were 
conducted about a week after the challenge, we asked participants to explain which sources they found the most useful, to identify which aspects of the engineering design process were the most difficult for them, to evaluate the utility of specific websites they visited, and other related questions.

Third, we collected adolescent-generated products, such as sketches and writings they produced throughout the challenge, their final report to the clients, and lists of the websites they visited as recorded by tracking software. We used these products as talking points for the interviews, such as by asking the participants to explain what they were thinking as they selected particular internet search terms.

\section{Data Analysis}

Collectively, the authors hold expertise in disciplinary literacy, teaching engineering design to high school students, and engineering education, and we brought these areas of expertise to bear throughout the analytic process. Specifically, the first author teaches content area literacy courses to pre-service engineering teachers; the third author teaches doctoral courses about engineering education to former engineers; and the second author is a full-time physics teacher who teaches pre-service science teachers how to integrate engineering design into their classroom instruction.

The first and second authors analyzed the data in two phases. In the first phase, we identified specific types of engineering design activity, and in the second phase, we connected each type of engineering design activity to particular literacy practices. Specifically, in the first phase of data analysis, we split the data into conversational turns, delineated each time that a different person spoke. 
We assigned each conversational turn with a code from Atman et al.'s (2007) Design Activity Coding Scheme. Following Hynes et al. (2011), we slightly modified the coding scheme by collapsing a few of the codes that were closely related, such as combining "analyzing feasibility" with "evaluating the design." The first author coded the participants' discussions using this scheme, while the second author coded $20 \%$ of the discussions. We obtained over $85 \%$ agreement in our codes, an indication that they were reliable (Lincoln \& Guba, 1985).

During the second phase of data analysis, the first and second authors read written transcriptions and/or viewed the video-recordings and mutually agreed on "literacy practice" codes that should be assigned to each conversational turn, as indicated by the patterns that emerged from the data (Smagorinsky, 2008). In other words, we identified the practices that adolescents engaged in each time they read or produced a text. We then noted which literacyrelated practices were associated with each stage of the design process. For instance, we noted that most instances of "literacy practice: annotate problem statement" occurred during conversational turns that had been coded "stage of engineering design: problem definition."

Finally, the first and second authors jointly noted areas of literacy-related difficulties that the adolescents faced as stated in their post-challenge interviews, and as indicated in their statements to their group members while they worked on the engineering design challenge. For instance, in the post-challenge interview, we asked Kayla (all names are pseudonyms) what she meant when she wrote "frame" in her final report to the client. She responded, "I think I was talking about the base right there [points to photograph of device]... but that was the part I didn't understand." We coded this statement as "difficulty with selecting words to label parts of the device." 
The third author observed the participants' activity throughout the design challenges and read through individual interview transcripts. Based on these experiences, he confirmed that the codes and conclusions regarding the adolescents' engineering design processes and literacy practices matched his perception of the adolescents' activity.

\section{Limitations}

This study was limited in the sense that it was only conducted with a limited number of participants, all of whom identified themselves as White, spoke English as a primary language, and excelled in school. Further research may be conducted with more academically, culturally, and linguistically diverse students to determine if they face different or additional literacy-related challenges as part of their engineering activity, or to determine whether they enact different literacy practices that also enhance their engineering designs.

\section{Findings}

Below, we divide the findings into the stages of the engineering design process and describe adolescents' literacy practices at each stage. We also identify areas where the adolescents faced literacy-related difficulties that ultimately impeded their design activity.

Insert Table 1 about here

\section{Defining the Problem}

As indicated by Table 1, the EWB Group devoted considerably more of their conversation to defining the problem than the AT Group. During this stage of the engineering design process, the EWB Group engaged in several literacy practices that shaped their 
subsequent design decisions. For instance, this group began by individually and collectively annotating the problem statement.

Samantha explained to Nick and Jack: "I just numbered the paragraphs, like this first paragraph talks about acquisition, and the second talks about the distribution, and then kind of acquisition again." Although Nick and Jack had already had underlined important aspects of the problem statement, they returned to it and re-annotated each paragraph to fit Samantha's observation that certain lines or paragraphs addressed issues related to water acquisition, others addressed issues related to water distribution, and others addressed issues related to water disposal. While collectively deciding on annotations they should use, the group members reread the statement several times, and they verbally summarized their understandings of the problem aloud to each other.

The group also collectively prioritized which issues in the problem statement most needed to be addressed, versus those issues that did not merit their attention. For instance, after reading one line to his group members, Nick decided "Okay, that's going to be the biggest one [problem] to address for sure.” The three group members had annotated that line with the word "distribution," and they then came to a consensus that distribution was going to be the "biggest" problem to address.

After reading another line from the problem statement, Nick stated, "I feel like....as far as how they get the water to that tank is fine," indicating that he thought the group did not need to modify that aspect of the existing design. This prioritization later enabled the group to structure their work as they decided to address the most pressing issue first, the second most pressing issue second, and so forth, while not devoting their time to the parts of the statement that were "not an issue." 
In addition to engaging in the literacy practices of annotating and prioritizing, the EWB Group also frequently identified gaps in available information, either through asking questions or through making inferences beyond what was explicitly stated in the problem statement. For instance, the group realized that they did not know how much energy the solar panel generated, so they called the EWB team leader to ask him whether it was sufficient to pump the water uphill to the water tower. As a second example, after reading the client's estimate of the average amount of total water used for washing per day, the adolescents inferred that the faculty at the orphanage would use more water to shower than the elementary-age children. This inference formed the basis for their later mathematical calculations.

In sum, the EWB Group engaged in multiple literacy practices that helped them to define the problem and which formed the basis for other stages of design process. These literacy practices ultimately structured the order in which they addressed problems; influenced the criteria by which evaluated their solution (e.g., a design would only be considered successful if it addressed water distribution, which had been identified as the "biggest" problem); shaped the types of information they sought during the information gathering stage; and influenced their later mathematical calculations and final designs.

The AT Group, by contrast, devoted very little conversation to the problem definition stage (see Table 1). They did not annotate or reread the problem, nor did they verbally summarize their interpretations of the problem. They did not discuss which problems were the most important to address (the device was at risk for buckling and could have physically injured the client) versus those problems that were not as important to address (the device could have been easier to transport in cars). In sum, when compared to the EWB Group, the AT Group engaged in very little comprehension-building activity (see Table 2). 
Insert Table 2 about here

Perhaps as a consequence, the AT Group did not develop a structured way of addressing the problem by noting which sub-components they should address first. Moreover, the group members remained unclear as to what the client wanted even after they submitted their final design to the client. For instance, Kayla touched the frame of the bathing transfer device in the last five minutes of the session, and stated, "I guess none of that is detachable then. I think that's maybe what they want more portable, the top part." Prior to this statement, no member of the AT Group had mentioned that the existing "top part" needed any improvements, nor had they addressed its portability in their final design.

Comments such as these indicated that the group was unclear about several components of the problem statement. Their confusion may have been mitigated if they had engaged in particular literacy practices at the problem definition stage, such as by annotating and rereading the problem, verbally summarizing their understandings of the problem, identifying aspects of the problem that were still vague or unclear to them, and making inferences or asking questions in order to clarify their understandings.

\section{Gathering Information}

Each group gathered information from different source types (see Table 3). Whereas the EWB Group relied heavily on the Internet for information, the AT Group instead preferred observing or manipulating physical devices. For instance, when the AT Group wanted to gather information about the degree to which the current device retained water, they poured glasses of water over the device. As a second example, the AT Group sought to gather information about the size of an average bathtub in order to determine what size their bathing transfer system 
should be. Rather than searching the Internet for this information, they wanted to measure one bathtub in the hotel where the design challenge was being held.

Insert Table 3 about here

Although we argue that their reliance on physical devices enabled the AT Group to gather valid information in the first instance, this reliance on physical devices was problematic in the second instance in a hotel where bathtub sizes varied based on room rates. As suggested by this example, one obstacle faced during this stage of the design process was that the AT Group had not developed conventional frameworks for evaluating which source types were appropriate to consult as they sought to answer specific questions.

The EWB Group, by contrast, was more likely to evaluate whether their current source gave them useful and reliable information, and when it did not, they either typed a different term into an Internet search engine or else they tried a different source type all together (see Table 3). For instance, when the group could not locate the cost of a 500-gallon polyethylene water tank online, they called the EWB team leader to determine the cost of the 500-gallon tank currently at the orphanage. In other words, they moved from one source type (consulting the Internet) to another (consulting an expert).

As a second example, when the search "What are the options for waste disposal?" yielded solutions that were unrealistic for their particular situation, they called Jack's dad, an alfalfa farmer, and asked him how they should dispose of the shower water. Jack's dad explained the difference between black water (sewage water), grey water (dirty but reusable water), and white water (fresh, potable water), and suggested that they build a drainage field for the gray shower 
water. Although the group did not take his suggestion to build the drainage field, they entered the term 'gray water' into a search engine, whose first entry was a Wikipedia page that emphasized gray water can be cleaned, recycled, and reused. After reading this page and others on gray water, they decided to filter and recycle the shower water in their final proposal, an aspect of their design that was praised by the civil engineer.

As indicated by these examples, we argue that the EWB Group's literacy practices included methods for dealing with difficulties in the search process, such as entering new search terms or moving flexibly across source types (e.g., experts, Internet sites). Unlike the AT Group, the EWB Group also continued to engage in several literacy practices they had begun in the Problem Definition Stage, such as verbally summarizing their understandings of the information they had gathered and identifying existing gaps in that information. Nick, for example, noted that several websites describing water tanks did not state what the tanks were made of, and he modified his search so he could specify the type of water tank that the EWB team should buy.

Because the groups' later designs were based on the information they had gathered, we argue that the ability to locate valid and specific information was important to the design process in the sense that it influenced the viability of the final design. For instance, if the AT Group had measured a tub that was larger than average, their proposed device would be too large to fit over most people's bathtubs. Accordingly, we assert that the EWB Group's literacy practices at this stage of the process - such as moving across different source types and trying new search terms based on information learned — ultimately enhanced their final designs, such as their decision to recycle the gray water. 


\section{Generating and Evaluating Ideas}

Among all of the data excerpts that were coded as "generating ideas" or "evaluating solutions," we found very few correlating literacy codes that indicated that the adolescents were searching for, reading, or producing multi-representational texts at these stages of the design process. One exception was Jaden from the AT Group, who sketched a few images on a piece of scratch paper but never revisited them or shared them with other group members.

Our analysis suggests that members of both groups generated a wide array of design ideas, but neither group recorded most (or any) of these ideas. As a result, when it came time to report their design to the clients, members of both groups expressed they did not remember several of their proposed solution elements. For instance, just before the AT Group decided they wanted to share their final design with the lab technician, Tyler questioned, "Wait, what did we do for the locks?," while Jaden asked, "And did we decide if we were going to do additional legs on the rails?," to which Ida replied, "I do not remember." Moreover, just as the groups did not remember several of their proposed design elements, they also did not remember the criteria by which they said they should evaluate their designs (e.g., cot materials should be mildewresistant).

We argue that these examples illustrate the importance of a variety of informal texts throughout the engineering design process, including texts that record initial ideas, even if they are never shared with the client or manufacturer. We infer that, due to the absence of these texts, several promising design elements were forgotten, and neither group could systematically evaluate their designs according to the criteria that they had articulated. 


\section{Communicating the Solution}

The AT Group communicated their solution to the man with muscular dystrophy and to the head technician at the Assistive Technology Lab, while the EWB Group shared their proposed design with the EWB team leader and a civil engineer. In all, although these stakeholders praised aspects of both designs, the EWB Group's design was deemed to be feasible (although probably not optimal), whereas the AT Group's design was not deemed to be feasible.

Specifically, the EWB Group's design used existing solar panels to pump potable water from a well into a water tank next to the kitchen, where the water would be used for drinking and cooking. The group also proposed to channel used shower water downhill through an underground cement basin, after which existing slow-sand filters would purify the water for reuse. The civil engineer praised the design for maximizing the precious resource of water, although she had questions about the cement basin, which was too large for the limited amount of water used for showering.

The AT Group proposed to add additional bars, straps, and legs to the existing bathing transfer device to keep it from buckling (see Figure 1 for their visual depiction of the bars and straps). They also proposed to change the existing cot into a folding lawn chair. The lab technician, however, ultimately deemed this device to unfeasible in part because it was unclear to him how he could build it. For instance, he could not envision how to incorporate the lawn chair into the existing frame when the group had not proposed structural changes that would enable the frame to hold a folding chair.

While seeking to communicate their designs to clients, the adolescents engaged in literacy practices in the sense that they were producing written/visual texts. As indicated by Table 2 , as the two groups were producing their final reports, they frequently asked for or gave 
feedback in three areas: (a) the type of representation they should use (e.g., asking whether they should use writing, a drawing, or a photograph to communicate a particular aspect of the design); (b) how they could improve their images (e.g., asking whether the bars on the image of the bathing transfer device looked thick enough); and (c) how they could improve their writing (e.g., asking whether a particular phrase made sense).

The professionals who evaluated the adolescents' final designs - as well as the adolescents themselves - believed that this revision process improved the clarity and quality of their final reports to their clients. That is, these final reports contained fewer misleading and confusing phrases and images because the adolescents had eliminated many of them from their initial drafts. Nonetheless, despite the helpfulness of peer feedback, members of each group frequently expressed frustration and a sense of difficulty at this stage of the design process, especially when selecting words that would communicate elements of their final design. One example from the AT Group will illustrate this difficulty.

During the Generate Ideas Stage of the design process, Tyler said, "So there's an attachment between this one and this one too," as he pointed to a specific location on one bar, then moved his hand in a line until it touched a specific location on another bar, to indicate spatially where the proposed attachment should be placed. The following exchange illustrates his attempt to communicate this idea to Kayla, who was writing the final report:

Tyler: Just call that the- - because, you've got the base, the thing, and then the cot. Kayla: Can you describe it in words so I can just type it? Tyler: I don't know. I don't know how to describe it in words. Jaden: I don't know how you would describe it, but it's like this [gestures over device]. 
Ultimately, the AT Group decided that "they [the people making the device] can just look at videos of us," if they needed clarification on which bar they were describing in their final report.

The EWB Group, too, had difficulty in choosing words to serve as labels. After experimenting with how to communicate the dimensions of the underground cement basin, they ultimately decided to draw three pictures and label them "front view, side view, and top view." Earlier, through talking and pointing to the map, they indicated that the front was the side closest to the showers.

In the post-challenge interviews, members of the EWB Group likewise experienced difficulty in explaining the visual because they never specified that the front of the tank was the side closest to the showers. In other words, in relation to a three-dimensional object, "front" depends on where one is standing in relation to the object, but the adolescents experienced difficulty in expressing directionality given the lack of a specified vantage point. In all, then, these examples suggested that the groups faced difficulty in transforming ideas that had previously been expressed through verbal speech and pointing gestures into written words and images.

\section{Implications}

This study suggests that certain literacy practices hold the potential to enhance adolescents' overall engineering design activity. These literacy practices include:

- rereading, annotating, and sharing/summarizing understandings of the problem statement;

- identifying gaps in information and addressing those gaps through strategies such as asking questions, making inferences, and recursively consulting different source types; - prioritizing which aspects of the problem most need to be addressed; 
- keeping track of ideas generated, included criteria and constraints; and

- giving and responding to feedback on different aspects of the final design.

Ultimately, we argue that the group that enacted more of these literacy practices, especially in the initial stages of the engineering design process, was able to more systematically address the client's needs.

This study also suggests that some adolescents face literacy-related difficulties with the engineering design process, including difficulties with understanding the problem statement, with identifying valid sources and source types for locating information, with keeping track of their design ideas, and with transforming ideas expressed via verbal speech, gestures, and objects into writing and images. Although this case study does not enable generalizability, it enables relatability as engineering teachers recognize aspects of their own students' literacy-related difficulties in the descriptions (Bassey, 1981). In this sense, we argue that this study has several implications for teachers who seek to support adolescents' engineering activity through providing embedded literacy instruction.

Specifically, we envision disciplinary literacy instruction in which teachers model for their students how engineers approach problems, including making their thought processes visible as they read problem statements, as they search for additional information, as they produce informal texts in order to reason through their designs, and as they generate formal texts to be shared with clients or other stakeholders. We envision that this approach would also include providing structured opportunities for students to evaluate and reflect on their own literacy practices at each stage of the design process (cf. Schoenbach, Greenleaf, \& Murphy, 2012). 
Due to the limited number of participants in this study, we do not presume that our description of these adolescents' literacy practices and literacy-related difficulties constitutes a comprehensive list. Rather, we believe that additional research with more diverse learners would identify additional literacy practices that can enhance adolescents' engineering activity, as well as additional difficulties they might face. By further identifying these practices and difficulties, researchers can begin to work with engineering teachers to develop and test instructional interventions that apprentice students into helpful disciplinary literacy practices, while at the same time addressing the literacy-related struggles that they face.

In all, we found that just as fundamental literacy — or the ability to understand and produce texts - is central to scientific inquiry, it can likewise be central to engineering design. Although more research can be done in this area, this exploratory study points toward ways in which engineering teachers might familiarize their students with literacy practices that hold the potential to enhance design activity. 


\section{Take Action!}

\section{Sidebar}

The following steps describe how high school engineering and science teachers can support students' engineering design activity through literacy instruction.

(1) During the problem scoping stage of the design process, model for students how engineers interpret clients' problem statements. Conduct think-alouds on a problem statement by modeling the types of thoughts that an engineer would think while reading it, or model for students how to annotate problem statements by asking questions, making inferences, and prioritizing.

(2) During the information gathering stage of the design process, make a list of the information students need to gather and ask students to identify possible sources for each piece of information. These sources may include manuals, code books, clients, experts, or Internet sources. Evaluate each source's ability to provide useful information and discuss how to modify the search process if one source proves to be unhelpful or incomplete.

(3) During the idea generation and evaluation phases of the design process, explicitly model for students how they can keep track of their formative ideas, mathematical calculations, and evaluative criteria through multimodal matrices, tables, lists, or other means. Evaluate each informal text's ability to record and systematically compare design ideas according to specified criteria and constraints.

(4) Prior to the communicate solution phase, show and evaluate models of reports to clients in terms of their persuasiveness, specificity, word choice, clarity, and other features. 


\section{References}

Atman, C. J., Adams, R. S., Cardella, M. E., Turns, J., Mosborg, S., \& Saleem, J. (2007).

Engineering design processes: A comparison of students and expert practitioners. Journal of Engineering Education, 96, 359-379.

Bassey, M. (1981). Pedagogic research: On the relative merits of search for generalization and study of single events. Oxford Review of Education, 7, 73-94.

Carmel, E. (1999). Concepts, context, and discourse in a comparative case study. International Journal of Social Research Methodology, 2, 141-150.

Carr, R. L., Bennett, L. D., \& Strobel, J. (2012). Engineering in the K-12 STEM standards of the 50 U.S. states: An analysis of presence and extent. Journal of Engineering Education, $101,1-26$.

Dym, C. L., Agogino, A. M., Eris, O., Frey, D. D., \& Liefer, L. J. (2005). Engineering design thinking, teaching, and learning. Journal of Engineering Education, 94, 103-120.

Heath, S. B. (1982). What no bedtime story means: Narrative skills at home and school. Language in Society, 11, 49-76.

Hynes, M., Portsmore, M., Dare, E., Milto, E., Rogers, C., Hammer, D., \& Carberry, A. (2011). Infusing engineering design into high school STEM courses. Available online at: http://ncete.org/flash/pdfs/Infusing_Engineering_Hynes.pdf

Katehi, L., Pearson, G., \& Feder, M. (2009). The status and nature of K-12 engineering education in the United States. The Bridge: Linking Engineering and Society, 39, 5-10.

Lincoln, Y. S., \& Guba, E. G. (1985). Naturalistic inquiry. Thousand Oaks, CA: Sage.

Moje, E. B. (2008). Foregrounding the disciplines in secondary literacy teaching and learning: A call for change. Journal of Adolescent \& Adult Literacy, 52, 96-107. 
National Assessment Governing Board. (2010). Technology and engineering literacy framework for the 2014 National Assessment of Educational Progress (NAEP). Washington DC: Author.

National Center for Engineering and Technology Education. (2012). Incorporating engineering design challenges into STEM courses. Available online at: http://files.eric.ed.gov/fulltext/ED537386.pdf

NGSS Lead States. (2013). Next generation science standards: For states, by states. Washington, DC: National Academies Press.

Norris, S. P., \& Phillips, L. M. (2003). How literacy in its fundamental sense is central to scientific literacy. Science Education, 87, 224-240.

Mehalik, M. M., \& Schunn, C. (2006). What constitutes good design? A review of empirical studies of design processes. International Journal of Engineering Education, 22(3) 519532.

Schoenbach, R., Greenleaf, C., \& Murphy, L. (2012). Reading for understanding: How reading apprenticeship improves disciplinary learning in secondary and college classrooms $\left(2^{\text {nd }}\right.$ ed.). San Francisco, CA: Jossey Bass.

Smagorinsky, P. (2008). The method section as conceptual epicenter in constructing social science research reports. Written Communication, 25, 198-226.

Street, B. (2000). Literacy events and literacy practices: Theory and practice in New Literacy Studies. In M. Martin-Jones \& K. Jones (Eds.), Multilingual literacies: Reading and writing different worlds (pp. 17-29). Philadelphia, PA: John Benjamins. 


\section{More to Explore}

Abts, L. (2011). Engineering design process portfolio scoring rubric. Available online at: https://innovationportal.org/resources/edppsr-download

Kelley, T. R. (2011). Engineers' notebook: A design assessment tool. Technology \& Engineering Teacher, 70(7), 30-35.

Reeder, K. (2005). Visual storyboarding provides a conceptual bridge from research to development. Technology Teacher, 65(3), 9-12. 


\section{Table 1}

Percentage of Conversational Turns Dedicated to Each Stage of the Engineering Design Process

\begin{tabular}{lll}
\hline & $\begin{array}{l}\text { AT Group } \\
(\mathbf{N = 1 4 1 2}) \\
\mathbf{\%}\end{array}$ & $\begin{array}{l}\text { EWB Group } \\
\mathbf{( N = 9 2 6 )} \\
\mathbf{\%}\end{array}$ \\
\hline Define problem & 3.7 & 18.3 \\
Gather information & 11.6 & 21.1 \\
Generate ideas & 30.5 & 16.5 \\
Evaluate ideas & 35.8 & 38.1 \\
Communicate solution & 18.5 & 6.0 \\
\hline
\end{tabular}


Table 2

Number of Literacy Practices Enacted at Each Stage of the Design Process

\begin{tabular}{|c|c|c|}
\hline & $\begin{array}{l}\text { AT Group } \\
(\mathrm{N}=145)\end{array}$ & $\begin{array}{l}\text { EWB Group } \\
(\mathrm{N}=339)\end{array}$ \\
\hline \multicolumn{3}{|l|}{ Define Problem } \\
\hline Annotate problem statement & 0 & 47 \\
\hline Identify gaps in information & 8 & 62 \\
\hline Summarize understandings & 0 & 39 \\
\hline Prioritize sub-components & 1 & 20 \\
\hline Reread & 1 & 10 \\
\hline \multicolumn{3}{|l|}{ Gather Information } \\
\hline Try new source type & 1 & 12 \\
\hline Enter new search term & 4 & 43 \\
\hline Summarize source & 0 & 25 \\
\hline Identify gaps in information & 0 & 32 \\
\hline \multicolumn{3}{|l|}{ Generate/Evaluate Ideas } \\
\hline Make a list of ideas & 0 & 0 \\
\hline Draw ideas & 4 & 0 \\
\hline List criteria or constraints & 0 & 0 \\
\hline \multicolumn{3}{|l|}{ Communicate Solution } \\
\hline $\begin{array}{l}\text { Ask for or provide feedback on } \\
\text { writing }\end{array}$ & 37 & 21 \\
\hline $\begin{array}{l}\text { Ask for or provide feedback on } \\
\text { visuals }\end{array}$ & 78 & 19 \\
\hline $\begin{array}{l}\text { Ask for or provide feedback on } \\
\text { representational type }\end{array}$ & 11 & 9 \\
\hline
\end{tabular}


Table 3

Types of Sources the Adolescents Consulted

\begin{tabular}{|c|c|c|}
\hline & $\begin{array}{l}\text { AT Group } \\
(\mathrm{N}=164) \\
\%\end{array}$ & $\begin{array}{l}\text { EWB Group } \\
(\mathrm{N}=195) \\
\%\end{array}$ \\
\hline Peer & 12.8 & 22.1 \\
\hline Expert & 17.6 & 27.2 \\
\hline Client & 0.0 & NA \\
\hline Internet & 3.7 & 50.8 \\
\hline Physical device & 65.9 & NA \\
\hline
\end{tabular}

